\title{
Catalytic Properties of Zeolites and Synthesized Superacid Systems During the Transformation of Model Reactions of Pentanes
}

\author{
Turlov s RA-B. \\ Heat Engineering and Hydraulics Department of \\ Grozny State Oil Technical University \\ g. Grozny, Russia \\ e - mail: r.turluev@mail.ru \\ Madaeva A. D. \\ Heat Engineering and Hydraulics Department \\ of Grozny State Oil Technical University \\ Grozny, Russia \\ e - mail: ANITA9770@mail.ru
}

\author{
Magomadova Marem .Kh. \\ Heat Engineering and Hydraulics Department of \\ Grozny State Oil Technical University \\ Grozny, Russia \\ e - mail: marem0300@mail.ru
}

Idrisova E.U.

Heat Engineering and Hydraulics Department of Grozny State Oil Technical University

Grozny, Russia

e - mail: idrisova999@mail ru

\author{
Magomadova Madina. Kh. \\ "Chemical technology of oil and gas Department of \\ Grozny State Oil Technical University \\ Grozny, Russia \\ e - mail : Emina8383@mail.ru
}

\begin{abstract}
Investigation of the catalytic activity and selectivity of the obtained products of various nature and composition of catalysts in the course of model catalytic reactions, cracking, isomerization, disproportionation. The study of the acid sites of these catalysts and their influence on the composition of the reaction products and the mechanism of conversion of specific $\mathbf{C} 5$ hydrocarbons. The study of the mechanism, speed and direction of individual stages of multistage reactions implemented scientific and industrial processes. Comparison of catalytic properties in the conversion of hydrocarbons of zeolites of different structure and other catalytic systems.
\end{abstract}

Keywords-Zeolites, superacid, superacid center, mechanism of chemical reaction, transformation of pentanes.

\section{INTRODUCTION}

Experimental pulsed microcatalytic apparatus was assembled on the basis of a chromatograph, which was modified in this way. All gas communications (from the input of raw materials to the entrance to the column) are thermostated at $100^{\circ} \mathrm{C}$. In order to avoid - the accumulation of high-boiling hydrocarbons on rubber gaskets, the standard dispenser crane is replaced on six-running in which such deposits practically were not observed. The dosing crane was also thermostatically controlled at $100^{\circ} \mathrm{C}$. A linear temperature rise in the furnace was made with the participation of the temperature programmer with the speed $20^{\circ} \mathrm{C} / \mathrm{min}$.

\section{THE METHODOLOGY OF THE EXPERIMENT}

Before conducting the experiment, the test samples of catalysts (zeolites, AAS and $\gamma-\mathrm{Al}_{2} \mathrm{O}_{3}$ ) with a fractional composition of $0.25 \div 40.5 \mathrm{~mm}$ were loaded into a quartz reactor, a sample of 0.15 g., the fractional composition of which, as the reactor is filled from the bottom of the reactor to the lower part of the catalyst boundary, varies from 2.0 to 0.1 $\mathrm{mm}$; then the catalyst and quartz were filled, the fractional composition of which changed in the reverse order. This backfill made it possible to distribute the flow of raw materials evenly throughout the catalyst bed. Then the reactor was placed in an oven, in which the temperature was raised from room temperature to $550^{\circ} \mathrm{C}$ with a heating rate of $20^{\circ} \mathrm{C} / \mathrm{min}$. The sample was kept at $\mathrm{T}=550^{\circ} \mathrm{C}$ for three hours in a stream of air. Then, 15-20 cycles of the reaction $\left(\mathrm{T}_{\text {reac. }}=400^{\circ} \mathrm{C}\right)$ followed, regeneration ( 1.5 hours) until a stable activity of the catalyst was achieved. Regeneration was carried out in a stream of dry air (flow rate $1.21 / \mathrm{h}$ ) at $\mathrm{T}=550^{\circ} \mathrm{C}$. Before the experiment, the regenerated sample was kept at a regeneration temperature in a helium current (flow rate $1.21 / \mathrm{h}$ ) for 0.4 hours to remove adsorbed water. After all the above operations were completed, the temperature in the furnace decreased in a current helium to Treac., And the sample was kept at this temperature for 0.5 hours to establish and stabilize the required flow rates of the carrier gas through the reactor. The flow rate of helium through the reactor varied, depending on the experimental conditions, in the range of $4-150 \mathrm{ml} / \mathrm{min} .(0.7 .10-7 \div 2.5 .10-8$ $\mathrm{m}^{3} / \mathrm{s}$ ), according to the calculations carried out in section 2.8 . Liquid raw materials were injected into the evaporator with a micrometric syringe in an amount of $8 \mu$ l. The temperature in 
the evaporator was set at $10^{\circ} \mathrm{C}$ above the boiling point of the hydrocarbon under study. Neopentane, gaseous at room temperature, was cooled in a refrigerator to $-5^{\circ} \mathrm{C}$ and injected into the evaporator in the liquid phase with a syringe cooled to the same temperature.

The activity and selectivity of the catalysts was determined by the first impulse of the initial hydrocarbon. The activity of the catalysts was monitored by conducting a reference experiment after each stage of research.

When studying the effect of Tact, the catalysts after regeneration were treated in a current of helium (flow rate 1.21 $/ \mathrm{h}$ ) in the range of temperatures $550-750^{\circ} \mathrm{C}$ for 2 hours. After carrying out these high-temperature treatments, the sample was not used in other studies.

The influence of the degree of coking of zeolites was studied by successive introduction of several pulses $(10 \div 50)$ of raw materials to the catalyst without intermediate regeneration of the samples.

The superacidic (superacid) catalyst (SCC) passed the preliminary activation at $\mathrm{T}=550^{\circ} \mathrm{C}$ for 2 hours in a helium flow (flow rate $1.21 / \mathrm{h}$ ). Since the SCC regeneration is not followed the experiment, the catalyst activity decreases by a factor of 10-20 due to a significant release of sulfuric acid from it) all the experiments performed were performed on a superficially activated sample of the sample.

Samples of AOC at temperatures $>60^{\circ} \mathrm{C}$ actively isolated hydrohalic acid, which also, like on the SCC, led to an irreversible loss of activity, therefore these catalysts underwent short-term activation ( $1 / 4$ hour) at $\mathrm{T}=50^{\circ} \mathrm{C}$ in current helium before the experiment.

\section{TRANSFORMATION OF PENTANES ON $\mathrm{AL}_{2} \mathrm{O}_{3}$ ALUMINOSILICATES AND HETEROGENEOUS SUPERACIDS}

The cracking of pentanes (neo-, iso-, n-pentane) on zeolites from the standpoint of the classical carbenium-ion mechanism should proceed through the unstable carbocations $\mathrm{CH}_{3}+$ (for all pentanes) and $\mathrm{C}_{2} \mathrm{H}_{5}+$ (for iso- and n-pentanes) the formation of which requires high energy getty costs [1].

Obviously, if a classical mechanism is implemented on zeolites for the cracking of pentanes, we should expect a number of fundamental regularities, in particular, a higher reactivity of iso- and n-pentanes compared to neopentane, similar compositions of the reaction products and a similar effect on the reaction acidic properties of zeolites.

The study of cracking of neopentane in the presence of mordenite [2], Y, and CWSC [3] type zeolites suggested that cracking of neopentane proceeds according to the protolytic cleavage mechanism of $\mathrm{C}-\mathrm{C}$ bonds through penta (tetra-) coordinated $\mathrm{C}-\mathrm{C}-$ carbonium ions with the formation of predominantly methane and butenes in a ratio close to stoichiometric:

$$
\begin{gathered}
H \\
/ \\
(\mathrm{Me})_{4} \mathrm{C}+\mathrm{H}^{+} \leftrightarrow\left[\mathrm{Me}--\mathrm{C}(\mathrm{Me})_{3}\right]^{+} \leftrightarrow \mathrm{CH}_{4}+(\mathrm{Me})_{3} \mathrm{C}^{+}
\end{gathered}
$$

It should be noted $[4,5]$ that on the zeolites of the protolytic cleavage of the $\mathrm{C}-\mathrm{H}$ bonds of neopentane does not occur, since iso- and n-pentanes in the primary products of the transformation are practically absent.

At the same time, it is known [6] that, in the presence of liquid super-acids of the type $\mathrm{HF}_{-} \mathrm{SbF}_{5}$, neopentane along with cracking undergoes isomerization through penta- (tetra-) coordinated $\mathrm{C}-\mathrm{H}$ carbonium-ion with the formation of isopentane (neopentyl Wagner-Meerwein rearrangement:

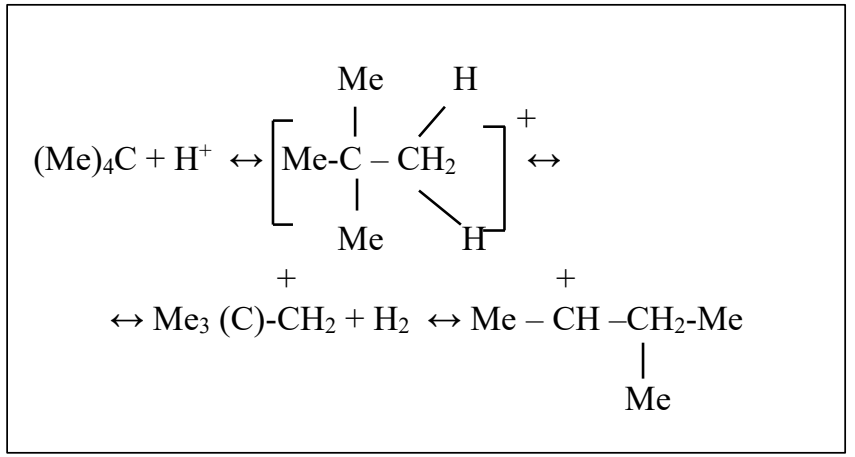

It is indicated [6] that the preferential protolysis of $\mathrm{C}-\mathrm{C}$ or $\mathrm{C}-\mathrm{H}$ bonds of neopentane is determined by the reaction temperature or catalyst composition, in our opinion, by the ratio of Bronsted and Lewis acids in the super acid. For example, in the superacid $\mathrm{HF}_{-} \mathrm{SbF}_{5}$ (2: 1 ratio), neopentane is predominantly cracked, and in the $\mathrm{SbF}_{5}$ system + traces of $\mathrm{HF}$ are isomerization.

Regularities of homogeneous superacid catalysis suggest that an increase in the relative concentration of BCC in zeolites and other solid acids should increase the selectivity of the protolysis reactions of $\mathrm{C}-\mathrm{C}$ bonds in hydrocarbons $\mathrm{C}-\mathrm{H}-$ bonds. As applied to pentanes, the protolysis of $\mathrm{C}-\mathrm{C}$ bonds is considered as the initiating stage of cracking reactions [4, 5], and the protolysis of $\mathrm{C}-\mathrm{H}$ bonds is considered to be isomerization and disproportionation reactions [4-6].

The superacid transformation mechanism of iso- and npentanes on zeolites can be implemented as follows [5]:

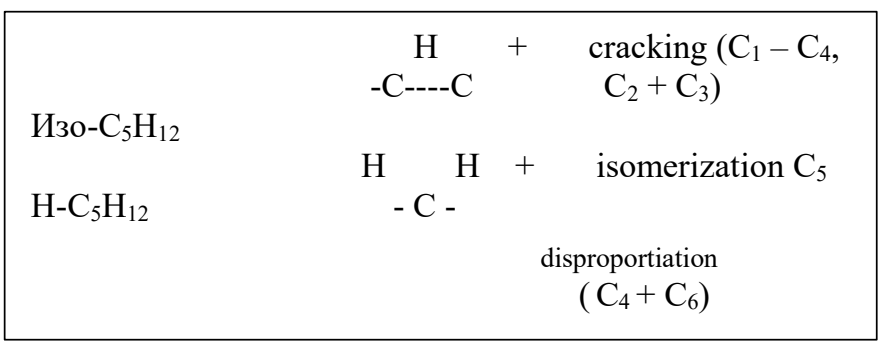

Based on the foregoing, we systematically investigated the transformation of neo-, iso- and n-pentanes, and also cyclopentane on $\gamma-\mathrm{Al}_{2} \mathrm{O}_{3}$ and AAS CEMCs that were subjected to the above-mentioned treatments, as a result of which, according to literary data and our physicochemical studies, their acidic properties, including the relative concentrations of BCCs and LACs in superacid centers of zeolites. In addition, we have investigated dealuminated fujazites (ICF-high-silica fujazites) with increased acidity [7-10] and previously not studied in the cracking of a number of pentanes. 
The use of $\gamma-\mathrm{Al}_{2} \mathrm{O}_{3}$ as a catalyst is due to the predominance of Lewis acidity in it [1].

To compare the catalytic action of zeolites and superacids, the conversion of neopentane on a heterogeneous superacid catalyst of the $\mathrm{ZrO}_{2} / \mathrm{SO}_{42}$ - type (SCC) was also studied. Lewis, as is known from literary data for heterogeneous superacids.

In addition, the conversion of n-pentane in the presence of applied aprotic organic superacids (AOC) of the $\mathrm{ACBr}$ type: $2 \mathrm{AlBR}_{3} / \mathrm{Al}_{2} \mathrm{O}_{3}$ (where $\mathrm{Ac}=\mathrm{RCO}$ ), which, according to [11], significantly exceeds the known $\mathrm{AlX}_{3}$-based catalysts, $\mathrm{Br}$ ) and the strongest proton superacids.

TABLE I. TRANSFORMATION OF PENTANES ON ZEOLITES AND SUPERACIDS

\begin{tabular}{|c|c|c|c|c|c|c|c|c|c|c|c|}
\hline \multirow[b]{2}{*}{$\begin{array}{l}\text { Raw } \\
\text { materi } \\
\text { al }\end{array}$} & \multirow{2}{*}{ 氧 } & \multirow{2}{*}{ 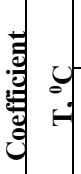 } & \multicolumn{8}{|c|}{$\begin{array}{l}\text { The composition of the products } \\
\mathrm{mol} / 100 \mathrm{~mol} \text { transformed raw materials }\end{array}$} & \multirow[t]{2}{*}{ W } \\
\hline & & & $\mathrm{C}_{1}$ & $\mathrm{C}_{2}$ & $\mathrm{C}_{3}$ & $\mathrm{C}_{3}^{/ /}$ & $\mathbf{C}_{4}$ & $\mathrm{C}_{4}^{/ 1}$ & $\mathrm{C}_{5}$ & $\mathrm{C}_{6}$ & \\
\hline $\begin{array}{l}\text { Neope } \\
\text { ntane }\end{array}$ & & $\begin{array}{l}0 \\
\text { : } \\
: 0 \\
0\end{array}$ & : & 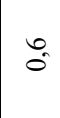 & î & ? & $\stackrel{i}{i}$ & $\therefore$ & ' & : & $\begin{array}{l}0 \\
\stackrel{0}{0}_{0}\end{array}$ \\
\hline $\begin{array}{l}\text { Isopen } \\
\text { tane }\end{array}$ & $y$ & $\begin{array}{l}0 \\
x \\
0 \\
-1\end{array}$ & & ' & $\stackrel{\circ}{=}$ & ' & $\stackrel{\dot{\pi}}{ }$ & ' & $\stackrel{\circ}{+}$ & 8 & $\begin{array}{l}\hat{a} \\
\hat{\alpha}\end{array}$ \\
\hline $\begin{array}{l}\text { Norm } \\
\text { al- } \\
\text { pentan } \\
\text { e }\end{array}$ & & $\begin{array}{l}0 \\
\stackrel{0}{x} \\
x \\
0 \\
0\end{array}$ & & & $\stackrel{\circ}{i}$ & & in & ' & $\frac{0}{\infty}$ & is & $\stackrel{0}{\hat{\theta}}$ \\
\hline \multirow{3}{*}{$\begin{array}{l}\text { Norm } \\
\text { al- } \\
\text { pentan } \\
\text { e }\end{array}$} & 武 & $\begin{array}{l}: \\
\stackrel{x}{x} \\
:\end{array}$ & $\infty_{0}^{\infty}$ & $\bar{f}$ & 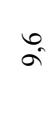 & $\stackrel{+}{i}$ & $m^{m}$ & $\hat{o}$ & in & $\hat{\sigma}$ & $\stackrel{\circ}{\stackrel{n}{=}}$ \\
\hline & of & 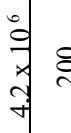 & 3. & = & $\stackrel{\infty}{r}$ & ' & 京 & ' & $\underset{\substack{n \\
s}}{i}$ & $\stackrel{0}{-}$ & $\begin{array}{l}\circ \\
\stackrel{0}{0}\end{array}$ \\
\hline & 氛 & $\begin{array}{l}0 \\
\text { a } \\
\stackrel{x}{2}\end{array}$ & 3 & $\because$ & $\tilde{\lambda}$ & ' & ôt & ' & $\begin{array}{l}\dot{y} \\
\dot{f}\end{array}$ & ò & $\begin{array}{c}\stackrel{m}{\infty} \\
\stackrel{\infty}{=}\end{array}$ \\
\hline
\end{tabular}

The authors of a number of works, according to literature data [3-11], studying the conversion of alkanes on solid superacids, showed their high activity and selectivity in various reactions, and the use of these systems allowed to significantly reduce the temperature of the reactions (compared with other solid acids) and get at the same time, the products of isomerization and disproportionation of alkanes, as well as cracking products.
TABLE II. MOLECULAR WEIGHT DISTRIBUTION OF THE CONVERSION PRODUCTS OF N-PENTANE TO AOC, $\mathrm{T}_{\text {REAC }}=50^{\circ} \mathrm{C}$, CONVERSION $\sim 3 \mathrm{WT} . \%$

\begin{tabular}{|c|c|c|c|c|c|c|c|c|c|c|}
\hline \multirow{2}{*}{$\begin{array}{l}\text { Ratio } \\
\text { AcBr: } \\
\mathrm{AlBr}_{3}\end{array}$} & \multirow{2}{*}{ 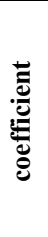 } & \multicolumn{8}{|c|}{$\begin{array}{l}\text { The composition of the products } \\
\text { mol / } 100 \text { mol transformed raw materials }\end{array}$} & \multirow[b]{2}{*}{$\underset{\text { W }}{\stackrel{\Xi}{\Xi}}$} \\
\hline & & 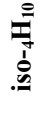 & 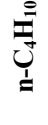 & 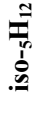 & 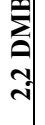 & 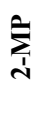 & $\sum_{\dot{n}}$ & $\stackrel{\underbrace{0}}{=}$ & $\begin{array}{l}\underbrace{ \pm}_{W} \\
\underbrace{ \pm}_{W}\end{array}$ & \\
\hline $1: 4,5$ & $\begin{array}{l}0 \\
0 \\
x \\
\hat{x}\end{array}$ & $\tilde{\simeq}$ & $\tilde{i}$ & $\widehat{\delta}$ & ?. & : & $\overrightarrow{0}$ & ? & $\stackrel{?}{-}$ & $\tilde{\tilde{s}}$ \\
\hline $1: 6,0$ & $\begin{array}{l}0 \\
0 \\
x \\
b \\
= \\
=\end{array}$ & 2 & $=$ & $\frac{n}{\sigma}$ & : & $\tilde{3}$ & $\overrightarrow{0}$ & है & $\Rightarrow$ & $\stackrel{\circ}{\circ}$ \\
\hline $1: 6,8$ & 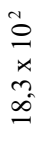 & $\stackrel{m}{r}$ & $\stackrel{\Xi}{-}$ & $\overrightarrow{\hat{a}}$ & of & 3 & $\overrightarrow{0}$ & के & ठे & $\stackrel{n}{0}$ \\
\hline
\end{tabular}

As was shown in the sources, the following series of catalytic activity of pentanes were obtained in the transformation of alkane carbon compounds on heterogeneous systems of the type $\mathrm{SbF}_{5}-\mathrm{SiO}_{2}-\mathrm{Al}_{2} \mathrm{O}_{3}$ :

\section{n-pentane $\geq$ isopentane $>$ neopentane.}

Similar studies carried out in [5, 7-10] during the transformation of iso- and n-pentanes, and we obtained a series of pentane activities during the cracking of neopentane on HCC: isopentane $\geq$ n-pentane $>$ neopentane (Table 1)

As can be seen from table 1, during the cracking of neopentane on the CCM, methane and butenes are formed in equimolar amounts (as well as on zeolites). It is also noteworthy that this produces $\sim 6$ moles (per 100 mol of converted neopentane) 2,2-DMB (which is the product of primary reactions), whereas on zeolites C6 hydrocarbons are observed only in trace concentrations.

The close compositions of the products of the transformation of neopentane on zeolites and solid superacids confirm the above-stated assumption about the analogy of the catalytic action of superacids and zeolites.

The same analogy is observed in the conversion of n-pentane.

Table 1 shows the MBP of the products of the conversion of $\mathrm{n}$-pentane on the initial and dealuminated fuzzite $\left(\mathrm{NH}_{4} \mathrm{NaY}\right.$ and VKF-4.6) and the SCCS-20.5. The MVR comparison of the npentane conversion products on these systems shows that the SCC activity is three orders higher than the zeolite activity, while the composition of the conversion products on the superacid catalyst is quite close (both qualitatively and quantitatively) to the ICF products -4.6

The main difference is the formation of small amounts of hydrocarbons $\mathrm{C}_{1}, \mathrm{C}_{2}$ on the VKF, which are not fixed on the 
CCM. The yield of the main product - isopentane, both on the $\mathrm{CCM}$ and on the CCF is the same and makes up $75 \div 80 \%$ of all conversion products, and these systems differ slightly in the content of $\mathrm{C}_{4}$ hydrocarbons.

It should be noted that the yield of isopentane in the conversion of n-pentane on the initial zeolite $\mathrm{Y}$ is significantly lower compared with the dealuminated sample.

In the primary reactions, the hydrocarbons $\mathrm{C}_{4}, \mathrm{C}_{6}$ and isopentane were identified on the faujasites studied, and only the isopentane on the CCM, the remaining products on both the zeolites and the CCM are secondary.

Thus, it can be stated that n-pentane at the ICF (at $\mathrm{T}_{\text {reac. }}=$ $200^{\circ} \mathrm{C}$ ) undergoes isomerization, and (to a large extent) disproportionation, and at the CCM only n-pentane isomerization is possible.

As can be seen from table 1, at low temperatures, the isomerization reaction of $n$-pentane is also capable of leading SVCCs. The yield of isopentane in the conversion of n-pentane at the SCCS-20.5 is 1.5 times lower than that at the VKF-4.6 and 2 times lower than the SCC. In addition, SVCCs (compared to HSC) at low temperatures exhibit rather high activity in the cracking reaction, as indicated by the formation of 23 moles of $\mathrm{C}_{3}$ hydrocarbons per $100 \mathrm{~mol}$ of n-pentane converted, which is 3 times higher than the yield on the CCF and 10 times, the output of these hydrocarbons in the CCM.

Small concentrations of $\mathrm{C}_{6}$ hydrocarbons (formed in primary reactions), as well as a relatively high yield of butane (also the primary products of the conversion of n-pentane) indicate a disproportionation reaction at the CEC.

Thus, at low temperatures, the reactions of the most active SVCCs, as well as HSCs, are capable of leading the reactions of disproportionation and isomerization of n-pentane, and unlike HCCs, they are capable of cracking substantially, whereas at a higher Trac. (as it was shown above), only the cracking and disproportionation reactions are characteristic for the SCCS, and isomerization products (at $\mathrm{T}>380^{\circ} \mathrm{C}$ ) are observed only in trace concentrations.

It is known that aprotic organic superacids (AOC) manifest extremely high activity with respect to paraffins (as compared with homogeneous and heterogeneous superacids, as well as zeolites). According to the data, these catalysts can operate at room temperatures and actively lead to cracking, isomerization, alkylation, and other reactions.

In our work, we studied the conversion of n-pentane to AcBr-type AOC. nAlBr $3 / \mathrm{Al}_{2} \mathrm{O}_{3}$ deposited on $\mathrm{Al}_{2} \mathrm{O}_{3}$ with different $\mathrm{AcBr} / \mathrm{AlBr}_{3}$ ratios (Table 2).

It has been established that solid superacid systems of the type $\mathrm{AcBr}$. nAlBr $3 / \mathrm{Al}_{2} \mathrm{O}_{3}$ at $\mathrm{T}_{\text {reac. }} 40-50{ }^{\circ} \mathrm{C}$ show extremely high catalytic activity in the conversion of n-pentane comparable with the activity of zeolites at $400^{\circ} \mathrm{C}$.

As can be seen from table 2, with an increase in the relative concentration of $\mathrm{AlBr}_{3}$ in the system, the catalyst activity increases 3 times, while the selectivity of the isomerization reaction does not actually change.
All n-pentane conversion reaction products (hydrocarbons $\mathrm{C}_{4}, \mathrm{C}_{5}, \mathrm{C}_{6}$ ) presented in the table are formed in primary reactions, i.e. It can be assumed that isomerization and disproportionation reactions occur on this catalyst as well as on zeolites and HCC.

It should be noted the high selectivity of the conversion of n-pentane on AOS to isopentane $(90 \%$ of the raw material is converted), whereas on the CCM zeolites the activity of the isomerization reaction is slightly lower $(\sim 68-75 \%$ of $n-$ pentane is converted to isopentane). AOC, in contrast to the $\mathrm{CCM}$, have good stability at Tracks. $=40^{\circ} \mathrm{C}\left(50^{\circ} \mathrm{C}\right.$ is the optimal temperature that provides the maximum yield of isopentane and the highest activity of $\mathrm{AOC} / \mathrm{Al}_{2} \mathrm{O}_{3}$ ), the results of the sequential introduction of eight pulses of n-pentane proved that the yield of isopentane decreases slightly from $85 \%$ (after the first pulse of raw materials) up to $75 \%$ (after the eighth pulse). When Treac. $=50^{\circ} \mathrm{C}$, the catalyst activity decreases sharply after the first pulse, which is associated with the entrainment of a significant part of the liquid AOC from the carrier $\left(\mathrm{Al}_{2} \mathrm{O}_{3}\right)$ at a higher temperature.

\section{POSSIBLE MECHANISM FOR THE CONVERSION OF PENTANES ON ZEOLITES AND SEPERACIDS}

The data presented indicates that neopentane is transforming at significantly higher rates than iso-, n-pentanes. Previously, such a pattern was found for initial zeolites of the type of SCCS and HY, as well as AAS [3-5, 7-10], and we established it for a series of dealuminated fuzzites and $\gamma-\mathrm{Al}_{2} \mathrm{O}_{3}$, as well as for all samples of the listed catalysts subjected to modification.

The nature of the transformation of neopentane does not depend on the type of catalyst used and the change in its acidic properties, including the BAC / LKC ratio, which indicates an extremely high stability of its structure.

In all studied acid catalysts, neopentane undergoes only cracking with the formation of predominantly methane and butenes with almost complete absence of pentanes in the product (isomerization) and hexanes (disproportionation).

The regularities established in this work are not interpreted within the framework of the classical carbenium-ionic theory and are in good agreement with the protolytic mechanism of neopentane $\mathrm{C}-\mathrm{C}$ bond cleavage previously proposed for homogeneous superacids [6] and zeolites of the Y and SVCC types [3-5, 7-10].

The minimum formation of isopentane and isohexanes indicates the stability of the $\mathrm{C}-\mathrm{H}$ bonds of neopentane, despite significant changes in the acidic properties of the catalysts, including an increase in the relative concentrations of LAC with corresponding treatments.

The formation of 2,2-dimethylbutane in primary reactions on the CCM, as well as the presence of trace amounts of $\mathrm{C}_{5}-\mathrm{C}_{6}$ hydrocarbons when neopentane is converted on zeolites, suggests that in the presence of strong Lewis acid sites, it is possible in principle to cleave $\mathrm{C}-\mathrm{H}$ bonds neopentane molecules by analogy with homogeneous superacid catalysis on $\mathrm{FSO}_{3} \mathrm{H}-\mathrm{SbF}_{5}$ systems. 


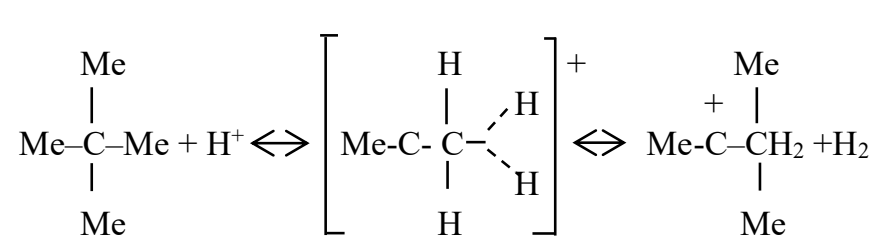

$\mathrm{C}_{5} \mathrm{H}_{11}{ }^{+}$carbenium-ion $\mathrm{C}-\mathrm{C}$ - neopentane molecule bonds:

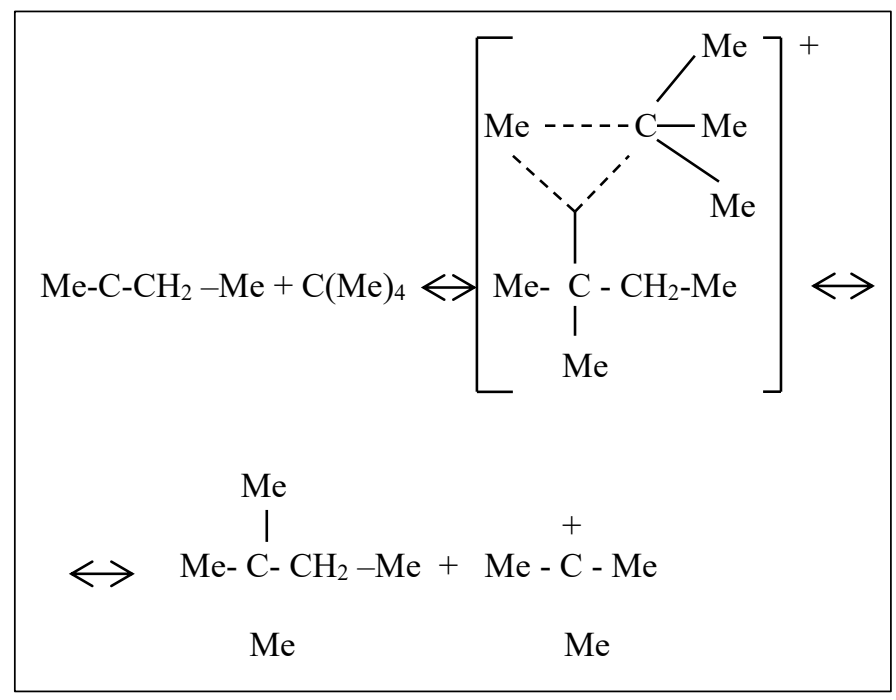

It should be noted that the proposed alkylolysis scheme does not explain the absence of pentanes in the reaction products and is unlikely due to obvious steric difficulties in the interaction of such bulky reagents as neopentane and tert- $\mathrm{C}_{5} \mathrm{H}_{11}+$ carbocation.

The cleavage of the $\mathrm{C}-\mathrm{H}$ bond of neopentane on HSCs can also occur as a result of the detachment of the hydride ion by the acid center of Lewis, as shown in [12], for the transformation of various alkanes on solid superacids. However, in this case, the above-mentioned neopentyl carbocation should also be formed, the isomerization of which ultimately should lead to the formation of C5 hydrocarbons, which are actually not detected in the reaction products. Neopentane in, when converted to SCC, as shown in Table 1, is only cracked, i.e. It can be assumed that SCC, being an aprotic superacid, also contains a certain proportion of BCCs capable of conducting protolytic cracking.

Due to the fact that the composition of the products of the transformation of neopentane to $\mathrm{HSC}$, SVCC, fujazite, $\gamma-\mathrm{Al}_{2} \mathrm{O}_{3}$ and AAS is very close, and these catalysts have different activities in the transformation of neopentane, it can be assumed that for splitting the C-C-bonds of its molecules are not required very strong acid sites, which are necessary for the protolysis of $\mathrm{C}-\mathrm{H}$ bonds.

The need for a small number of acid sites for the protolytic cracking of neopentane is indicated by the rather active splitting of the $\mathrm{C}-\mathrm{C}$ bond on $\gamma-\mathrm{Al}_{2} \mathrm{O}_{3}$. The absence of any catalytic activity in the conversion of neopentane to $\alpha-\mathrm{Al}_{2} \mathrm{O}_{3}$ (treated at $1120^{\circ} \mathrm{C}$ for 3 hours), as well as according to the literature data, pure silicalite has no acid centers.

It should be noted that the obtained distribution of products on the acid sites of catalysts that are completely different in strength is not related to the course of the process of thermal cracking of neopentane. Experiments have shown that the molecule of this hydrocarbon is not subject to thermal cracking even at $550{ }^{\circ} \mathrm{C}$. These results are confirmed by the data from the literature on the transformation of neopentane $\left(600^{\circ} \mathrm{C}\right)$ on quartz.

The higher rate of cracking of neopentane on an SCCS (which is also noted in $[4,7]$ ) compared to dealuminated fuzzites, as well as AAS and $\gamma-\mathrm{Al}_{2} \mathrm{O}_{3}$, suggests that the conversion of pentanes on zeolites is not determined by their molecular sieve properties.

Taking into account the fact that the neopentane molecule having a critical diameter of 6.9A0 (angstroms), under any conditions (even taking into account the effect of channel expansion in the AHCC $\sim$ by $1 \mathrm{~A} 0$ ) cannot theoretically penetrate into the pores of the zeolite, it can be assumed that it turns into acidic the centers of its surface. Such an assumption corresponds with the data, where it is shown that the 2,2-DMB molecule (critical diameter 6, ZA0), when converted to the SCCC, cannot penetrate into the channels of the zeolite and undergoes a preliminary stage of isomerization on the outer surface, turning into such isomers that can easily diffuse into the zeolite channels and undergo further transformations in them.

The "shuttlecock-box" model proposed in the literature is untenable in the case of neopentane, since, due to the specificity of the structure of the methyl groups, the molecules are not able to bend to the sides according to the type of shuttlecock as they enter narrow CWCC input channels. In order to implement this model, it seems that a strong electrostatic field directed at the molecule is needed, and SVCCs cannot create such a field, as noted in the literature.

Thus, the increased rate of transformation of neopentane at the CEMF is probably due to the presence of stronger active sites (literature sources) in them as compared to fujazites and other studied catalysts, as well as to the specific nature of the structure of CWCC.

The reasons for the high reactivity of $\mathrm{C}-\mathrm{C}$ bonds and the stability of $\mathrm{C}-\mathrm{H}$ bonds of the neopentane molecule in the presence of solid acid catalysts remain unclear.

In contrast to neopentane, the transformation of $n$ - and isopentanes in the presence of CEMCs is significantly affected by their modification, leading to a change in the selectivity of the primary parallel cracking reactions, on the one hand, and isomerization and disproportionation, on the other hand.

\section{CARBONIUM-ION MECHANISM}

The classic mechanism for the conversion of hydrocarbons, including the formation of carbenium-ion, $\beta$ - decay, rearrangement, disproportionation, isomerization and other reactions has a great popularity, which is based on the fact that 
it is easy to explain the mechanism of action of various systems (superacids and solid catalysts) having acid sites.

At the same time, there are a number of principal laws of transformation of individual hydrocarbons on zeolites, zeolitecontaining and amorphous catalysts, which are difficult to explain using the carbenium-ionic mechanism of the reaction (known from literature sources):

- cracking of aliphatic hydrocarbons with the number of carbon atoms less than seven;

- the formation in the composition of the products of the primary reactions of methane, ethane, ethene;

- the formation of propane and butanes as primary products during cracking of alkanes C6 and less;

- the formation as primary products of hydrogen, paraffins $\mathrm{C}_{1}-\mathrm{C}_{4}$ and olefins $\mathrm{C}_{5}$ in the conversion of $\mathrm{n}-\mathrm{C}_{6}, 2-\mathrm{MP}, 3-\mathrm{MP}$, 2,3-DMB at SVCC;

- the absence of isomers of the initial hydrocarbon during the cracking of paraffins and their presence during the cracking of olefins, naphthenes and aromatic hydrocarbons;

- flow cycle "accession-splitting" for low molecular weight paraffins and olefins, which causes the formation in the products of low molecular weight and higher molecular weight hydrocarbons compared to the original;

- the formation of only saturated products in the cracking of n-butane, n-pentane and n-hexane on NM at low temperatures;

- unexpectedly high reactivity of neopentane on $\mathrm{H}$ mordenites;

- the reverse (as compared with the classical) reactivity of pentanes (neo $\mathrm{C}_{5}>$ from $\mathrm{C}_{5}>\mathrm{n}-\mathrm{C}_{5}$ ) on zeolites and $\mathrm{AAS}$;

- fundamental differences in the molecular weight distribution of the products of neopentane conversion on the one hand, and iso- and n-pentanes on the other;

parallel formation in the primary reactions of hexanes and cyclic hydrocarbons during the cracking of cyclohexane on the FSCC faujasite.

By analogy with the mechanism of reactions on superacids in the homogeneous and heterogeneous phase, for describing the first cracking stage on zeolites, a number of hypotheses for the formation of a carbocation have been proposed;

- with the separation of the hydride ion on the LCC:

- separation of the hydride ion by a strong BCC;

- adsorption on BCC olefins obtained from thermal cracking of the source of hydrocarbons;

- during the polarization of the raw material molecule under the influence of strong electric fields in the pores of the zeolite;

- at the addition of a proton, detached from a strong BAC, with the formation of a penta- (tetra-) coordinated carbon atom (non-classical carbonium-ion).

The analogy of the catalytic action of liquid superacids and heterogeneous acid catalysts, which is close to the MWP of the conversion products of individual hydrocarbons on both systems (assuming that there are superacid active centers at heterogeneous contacts), shows that the carbocations adsorbed on the surface are subject to the same transformations that are characteristic for homogeneous catalysis.

The protolytic mechanism for the conversion of low molecular weight hydrocarbons with the participation of nonclassical carbonium ions is now generally recognized. According to literary sources, the protolytic cracking of nparaffins is energetically more advantageous to $\beta$-cracking through carbenium ions and is approximately equivalent to cracking branched alkanes.

Protonated paraffins are considered in the literature as complexes of the classical carbenium ion $\left[\mathrm{CnH}_{2} \mathrm{n}+1\right]+$ and water molecules. Calculations using the molecular orbitals method showed that the non-classical carbocation can be an intermediate structure in the formation and transformation of the classical carbocation.

The mechanism of protolytic cracking of hydrocarbons can be represented by the scheme [6]:

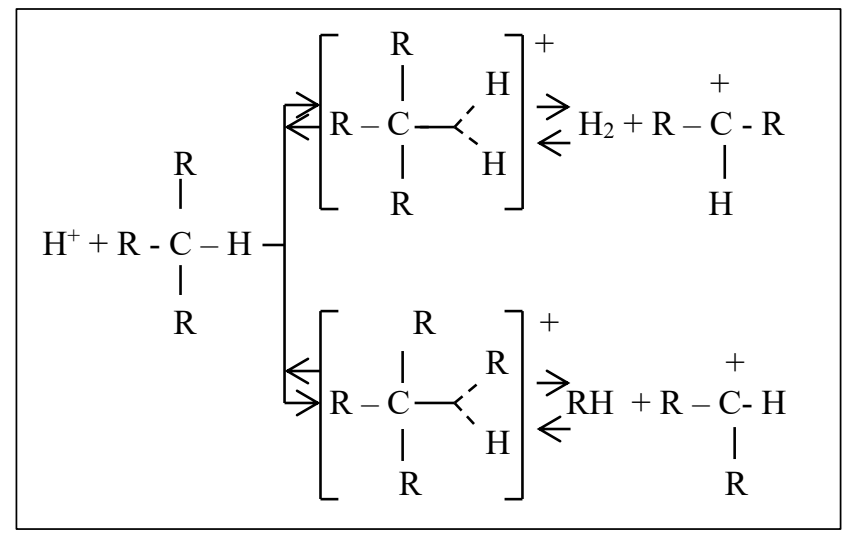

This reaction mechanism is identified by the rapid deuterohydrogen exchange of paraffins without their skeletal isomerization and the presence of molecular hydrogen and light paraffins $\mathrm{C}_{1}, \mathrm{C}_{2}$ in the primary products of cracking.

Isomerization transformations of saturated hydrocarbons in solutions of superacids $\mathrm{HF}-\mathrm{SbF}_{5}$ and $\mathrm{FSO}_{3} \mathrm{H}-\mathrm{SbF}_{5}$ according to Ola [6] and other sources flow in several possible directions:

- protonation of $\mathrm{C}-\mathrm{C}$ bond:

- protonation of $\mathrm{C}-\mathrm{H}$ bond.

To clarify the mechanism of the conversion of n-pentane on the above-mentioned superacids, as well as the $\mathrm{AlCl}_{3}, \mathrm{AlBr}_{3}$, $\mathrm{AlCl}_{3}: \mathrm{C}_{2} \mathrm{H}_{5} \mathrm{Cl}$ systems, the isomerization reaction of pentanes labeled in 1,2, -3-positions of the molecule with the radioactive carbon isotope $14 \mathrm{C}$ has been studied in the literature. The authors did not manage to coordinate the distribution of labeled carbon in the isomerization products with any of the concepts of the isomerization mechanism (through the carbenium ion, 13 chemisorption, the intermediate formation of the protonated cycloparaffin structure of the methylcyclobutane structure, and the penta- (tetra-) -coordinated carbonium ion [6]. It is assumed that the skeletal isomerization of n-pentane on these systems 
proceeds simultaneously in several directions with a predominance of one o or several of them, depending on the nature of the catalyst and the experimental conditions. Similar assumptions were made earlier by Ola during the transformation of neopentane in the presence of homogeneous superacids $\mathrm{HF}-\mathrm{SbF}_{5}, \mathrm{FSO}_{3} \mathrm{H}-\mathrm{SbF}_{5}$ [6]. According to [6], the conversion of neopentane proceeds through one of the mechanisms in appropriate conditions:

In our opinion, the predominant direction of the reaction $(\mathrm{C}$ $\mathrm{C}$ or $\mathrm{C}-\mathrm{H}$ communication protocol) is associated with the predominance of Brönsted or Lewis acidity in the system. Typical Lewis acid - SbF5 (always containing traces of HF) or $\mathrm{FSO}_{3} \mathrm{H}-\mathrm{SbF}_{5}$ will be most effective in isomerization, the HF$\mathrm{SbF}_{5}$ system (2:1) is more active cracking, it is dominated by Bronsted acidity.

Superacid acids have an extremely high ability to serve as proton donors, the $\mathrm{FSO}_{3} \mathrm{H}-\mathrm{SbF}_{5}$ system can even protonate $\mathrm{C}-$ $\mathrm{H}$ bonds of methane. Ola exploring the conversion of methane on systems such as $\mathrm{FSO}_{3} \mathrm{H}-\mathrm{SbF}_{5}$. showed that he undergoes a rapid deuterium-hydrogen exchange at $50-60{ }^{\circ} \mathrm{C}$ according to the scheme:

$$
\mathrm{CH}_{4} \underset{\mathrm{DSO}_{3} \mathrm{~F} / \mathrm{SbF}_{5}}{\stackrel{\mathrm{DF} / \mathrm{SbF}_{5}}{\longrightarrow}}\left[\mathrm{CH}_{4} \mathrm{D}^{+}\right] \stackrel{-\mathrm{H}+}{\longleftrightarrow} \mathrm{MeD}
$$

Extremely interesting results were obtained by Volpin, Akhrem, Orlinkov in [11] and other works. It was found that the Acx: $\mathrm{zAlx}_{3}$ system $(\mathrm{x}=\mathrm{Cl}, \mathrm{Br}$; $\mathrm{Ac}=\mathrm{RCO})$, called aprotic organic super acids (AOS), are extremely active with respect to paraffins: at room temperature (and below) they effectively catalyze fragmentation, isomerization, alkylation of n-alkanes and other processes, which qualitatively distinguishes these systems from the corresponding equimolar complexes, which are not active to paraffins under such mild conditions, as well as other catalysts based on Lewis acids. It should be noted that the activity of AOS in cracking and isomerization considerably surpasses all the catalytic agents based on Lewis acids and proton superacid systems described in the literature. The key stage of the transformation of n-alkanes on AOS as well as on superacids is the generation of carbenium ions under the action of an electrophilic complex:

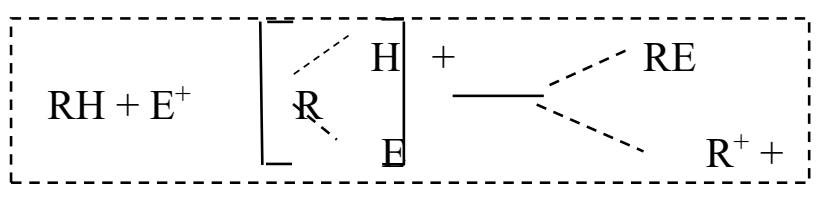

Recently, there have been published many publications on the conversion of hydrocarbons on solid superacids and zeolites by a mechanism involving the stage of protonation and the formation of a penta (tetra-) coordinated carbonium ion. There is evidence in the literature that during the protolysis of $\mathrm{C}-\mathrm{C}$ and $\mathrm{C}-\mathrm{H}$ bonds of molecules of iso- and $\mathrm{n}$-butanes in solutions of liquid superacids, n-butane gives products in the order $\mathrm{CH}_{4}>$ $\mathrm{C}_{2} \mathrm{H}_{6}>\mathrm{H} 2$, and isobutene $\mathrm{H}_{2}>\mathrm{CH}_{4}>\mathrm{C}_{3} \mathrm{H}_{8}$. At the same time, in the presence of solid superacids of the type $\mathrm{SbF}_{5}-\mathrm{SiO}_{2} ; \mathrm{SbF}_{5}-$ $\mathrm{Al}_{2} \mathrm{O}_{3}$ and others, there is no molecular hydrogen in the products of iso- and n-butanes, and the concentration of methane is low. The different behavior of homogeneous and heterogeneous superacids in catalysis, the authors explain by lower acidity of solid contacts. The $\mathrm{FSO}_{3} \mathrm{H}-\mathrm{SbF}_{5}$ solution exhibits $\mathrm{H} 0<20$ acidity and can prototype both $\mathrm{C}-\mathrm{C}$ and primary $\mathrm{C}-\mathrm{H}$ bonds of alkanes, and the supported catalyst has $\mathrm{H} 0=13.75 \div 14.5$ and is capable of protonating only $\mathrm{C}-\mathrm{C}$ bonds of alkanes.

Active superacid centers of solid superacids of the $\mathrm{Al}_{2} \mathrm{O}_{3} /$ $\mathrm{AlCl}_{3}$ type are surface cations $\mathrm{Al}_{3}+$ with an electron deficiency AlO-Al-O-AlCl 3 , which belong to the Lewis superacidic centers. Such a center attacks the $\mathrm{C}-\mathrm{H}$ and $\mathrm{C}-\mathrm{C}$ bonds of alkanes with the formation of a carbonium ion.

This mechanism explains well the results obtained for the transformation of n-pentane, n-hexane and other alkanes on solid superacids.

The analogy of the catalytic action of liquid and solid superacids and zeolites allowed the use of the Ola mechanism to interpret the results of the conversion of various hydrocarbons on zeolites.

As a test reaction indicating such an analogy, we can consider the reaction of the transformation of neopentane. We have already shown above that, depending on the type of superacid, the BKTs / LKC ratio, and reaction conditions, both $\mathrm{C}-\mathrm{C}$ and

$\mathrm{C}$-H-bonds of neopentane with the formation of significant amounts of methane and $\mathrm{C}_{4}$ hydrocarbon (C-C-protolysis) and isopentane (at $\mathrm{C}-\mathrm{H}$ protolysis). The transformation of neopentane on fujazites [3] showed that only $\mathrm{C}-\mathrm{C}$ bonds of neopentane are subjected to splitting (under any experimental conditions) to form equimolar amounts of methane and $\mathrm{C} 4$ hydrocarbons in primary reactions (the yield of the remaining $\mathrm{C}_{2}-\mathrm{C}_{3}$ products is insignificant, and they are secondary). Trace concentrations of isopentane in the products indicate the possibility of protolysis of the $\mathrm{C}-\mathrm{H}$ bond of the molecule, at a certain ratio of $\mathrm{BCC} / \mathrm{LCC}$ in the zeolite. Similar results were obtained later in $[7,8]$ during the transformation of neopentane on the SCCC, and also presented in [4] during the transformation on AAS.

It is known from the literature that the acidity of the strongest acid sites of zeolites does not exceed Ho $=-12.8$, while the acid sites of homogeneous superacids have Ho $\leq 20$. Thus, it can be assumed that the acid sites of zeolites are not sufficiently strong to protonate the primary C-H-bonds of neopentane, and what is observed in the presence of homogeneous Lewis acids. Similar conclusions were made in the conversion of alkanes on homogeneous and heterogeneous acids. The authors indicated that the lower strength of the acidic centers of solid superacids does not allow the cleavage of the primary $\mathrm{C}-\mathrm{C}$ and $\mathrm{C}-\mathrm{H}$ bonds of alkanes, whereas the $\mathrm{C}-\mathrm{H}$ bonds of the secondary and tertiary carbon atoms can split at these centers.

It can be assumed that a change in the ratio of BCC / LCC in zeolites may lead to an increase in the proportion of the protolysis reaction of $\mathrm{C}-\mathrm{H}$ bonds during the conversion of neopentane, and also increase the share of these reactions during the conversion of hydrocarbons with $\mathrm{C}-\mathrm{H}$ bonds at the secondary and tertiary carbon atoms. 


\section{CONCLUSION}

An analysis of the published data showed that the results of numerous studies on the conversion of low molecular weight alkanes on acid catalysts are most fully interpreted within the framework of the protolytic theory of Ola. In general, the mechanism of transformation of alkanes on catalysts having superacid centers can be represented as follows. Initially, the proton activates the $\mathrm{C}-\mathrm{C}$ or $\mathrm{C}-\mathrm{H}$ bond (protolysis) of the alkane molecule, forming a carbonium ion. The carbocation can then turn into paraffins (hydride transfer reaction), olefins (proton elimination reaction), or react with paraffins due to cleavage of the $\mathrm{C}-\mathrm{C}$ bond (alkylolysis) - a disproportionation reaction. The carbocation can also join at the site of the double bonds of the intermediate olefins (alkylation) and activate the $\mathrm{C}$ $-\mathrm{C}$ bond, leading to $\beta$-fragmentation.

It was established that each reaction takes place in a certain, relatively narrow range of acidity of the active center, therefore, acting on acid sites, one can control the selectivity of the corresponding reactions occurring on zeolites [3-5, 7-10].

Controlling the $\mathrm{C}-\mathrm{C}$ and $\mathrm{C}-\mathrm{H}$ cleavage reactions of saturated hydrocarbons is an important practical task. According to the literature data, this control is possible due to the modification of zeolites that change the relative concentrations of BCC / LCC in zeolite in various ways, which also can have a significant impact on the transformation route (protolytic cracking - $\beta$-cracking).

\section{References}

[1] M.L. Putzma, Mechanisms of catalytic conversion of hydrocarbons on zeolites. book: Chemistry of zeolites and catalysis on zeolites, M .: Mir, Vol. 2, pp.5-125, 1980.

[2] H.K. Beyer, P. Reti, J. Horwath, "Beitrage zur kentnis der Krack Reactionen" Mechanismen der an Mordeniten Verlaufenden Katalitischen Reactionen von Paraffinischen Kohlenwasserstoffen, Acta CMm. Acad. Sci. Hung, 1982, Vol. 102, pp. 199-207.

[3] S.N. Khadzhiev, T.M.Gairbekov, K.V.Topchieva, A.M. Rossinsky, "Cracking Neopentava on Y-type Zeolites," Report of Academy of Sciences of the USSR, 1985, Vol. 281, No. 4, pp. 864-865.

[4] A.M. Russian, Regularities of the cracking of hydrocarbons on heterogeneous acid catalysts: Thesis. Cand. chemical sciences. Groznuy, 1987.

[5] T.M. Gairbekov, C.H. Hadzhiev, A.M. Russian, "Cracking of neopentane on ultrahigh-silica zeolites", Kinetics and catalysis, 1988, Vol.29, pp I490-I492.

[6] G.A. Ola, "Carbocations and electrophilic reactions," Chemistry achievements, Vol.44, №5, p. 793, 1975

[7] T.M. Gairbekov, R.A. Turluev, A.K. Manovyan, S.N. Khadzhiev, "The mechanism of decomposition of isopentane on ultrahigh-silica zeolites," Petrochemistry, Vol. 28, № 5, pp.662-666, 1988.

[8] T.M. Gairbekov, R.A. Turluyev, A.K. Mayakovyan, S.N. Khadzhiev, "Cracking of normal pentane on ultrahigh silica geoliths," Kinetics and catalysis, Vol.30, № 2, pp.480-484, 1989.

[9] A.M. Rossinskii, T.M.Gairbekov, S.N. Knadziev, "Some pecularities of cyclohexane conversion on zeolite catalysts," React. Kinet.Catal. Lett., Vol. 28, №2, pp. 347-352, 1985.

[10] T.M. Gairbekov, M.E. Volpin, S.N. Khadzhiev, R.A.V. Turluev, A.V Melnichenko, "Superacid properties of zeolites in catalysis," Seventh Petrochemical Symposium, Report Kiev, October 15-20, 1990.

[11] Mark Volpin, Irena Akhrem and Alexander Orlinkov, "Aprotic Organic Superacids-Officient reagents and catalysts for transformations of alkanes and cycloalkanes under mild conditions, " New J. Chem., Vol. 13, №10$11,1989$.
[12] M. Marczewski, "Mechanism of n-alkane transformation over solid superacid of lewis character $\mathrm{Al}_{2} \mathrm{O}_{3} / \mathrm{AlCl}_{3}$ " J. Chem. Soc. Faraday, Pt.1, Vol.82, №6, pp. 1687-1701, 1986 